Received: November 10, 2017

Revision received: April 15, 2018

\title{
Design and Implementation of Android-based Flip Class Visualization in Physical Education
}

\author{
Hui Ming \\ Sanquan College of Xinxiang Medical University
}

\begin{abstract}
This paper systematically describes the concept and classification of Flip Class and Micro-Course Online Video and analyzes the applicability of MCOV from the perspective of knowledge attributes. Out of that pops the basic model of FC instruction as combed. Then three education models of MCOV-based FC, i.e. O-I, A-B and $\mathrm{O}-\mathrm{AB}-\mathrm{AB}$ are proposed. Here also comes the idea of teaching design flow and gives a set of instructional design tools in this model.
\end{abstract}

\section{Keywords}

Flip Class • Visualization • Physical Education

${ }^{1}$ Correspondence to: Hui Ming (MA), Sanquan College of Xinxiang Medical University, Xinxiang 453003, China. Email: 091049@xxmu.edu.cn 
There are discrepancies among students, but classroom instruction in traditional schools cannot educate students in accordance with their aptitudes for various objective reasons. Thought this fact is well known to all schools and teachers, the "classroom knowledge transference" as specified in the traditional education cannot truly realize stratified teaching model, so that it is impossible to let every student fully understand any knowledge point (i.e. the pass level that teachers think) (Hwang, Lai \& Wang, 2015; Zengin, 2017). As an emerging model, the FC enables students to become the main body of knowledge learning based on the information technology, realize the turnover of when and where knowledge transference and internalization occur. With this model, students can learn at their own paces, truly achieve stratified and individualized learning model, so that the contradictions in current classroom instruction in schools are effectively suppressed.

The core of FC instruction is digital education resources, while the birth of MCOV, a short and lean video teaching resource as newly discovered, lays a good foundation for the popularization and development of FC instruction (Liou, Bhagat \& Chang, 2016). With the characteristics of fragmentation, visualization, etc. it has become one of the best teaching resources for developing FC instruction (Allen-Ramdial \& Campbell, 2014; Subramaniam, Ahn, Fleischmann \& Druin, 2012). The perfect combination of FC and MCOV provides a new idea for classroom education reform. Survey results of foreign scholars show that in the traditional classroom teaching model, $50 \%$ of students failed in English exam, and 44\% in mathematics exam every semester. After introducing the FC model, the students who has failed the two exams have dropped to $19 \%$ and $13 \%$, respectively. Such teaching effect has won the favor of many frontier teachers at home and abroad (Zainuddin \& Attaran, 2015).

College sports is an important part of education in colleges and universities. It is an important means to promote students' health and enrich campus cultural life to build a harmonious campus. Therefore, the purpose of strengthening the construction of sports culture is to improve students' physical quality, comprehensively promote students' physical and mental health, and comprehensively promote students' physical and mental health, so as to cultivate high-quality talents with comprehensive abilities, the diversification of the teaching methods of physical education provides an important guarantee for this purpose. The FC instruction model adjusts the order of a certain part of the traditional classroom courses and enables students' active learning after class or self-explanation in class (Mustapha, Rahman \& Yunus, 2010; Muir \& Geiger, 2016). The FC model has raised the bar for the students' pre-class practices and is conducive to foster their innovative and practical skills. This paper discusses the effect of FC model in epidemiology course.

\section{Micro lesson and flip classroom overview}

FC

The author holds three opinions on the FC instruction model:

(1) The students' learning knowledge in the FC instruction model has not changed in the process, and still in the order of the "new knowledge learning - knowledge internalization"; 
(2) What the FC turns over is the time and place of new knowledge learning and knowledge internalization from "in-class - after-class" to "after-class - in-class";

(3) The key to success in FC instruction model is that each student can maximize learning effect with the help of information technology in the new knowledge learning phase, and feed teachers with effective learning information to help teachers improve their teaching programs. Based on the above three opinions, this paper carries out the study on instructional design of MCOV-based FC.

\section{Basic FC instruction model}

Many scholars at home and abroad have made extensive studies on the FC since its inception, even they never stopped studying it till the rise now (Gouia \& Gunn, 2016; Yang, 2017). The most universal FC model is nothing less than the FC instruction models, while the earliest one is the exploration-reversal-application type built by Professor Ramsey Musallam after many years of teaching practice. As a type of cyclic FC, this model introduces guided inquiry instruction methods as a means for students to explore new knowledge to help students perform flipping learning using online instruction videos and learning tasks. Eventually it is likely for them to achieve the purpose of knowledge internalization with various activities launched in class.

In traditional instruction model, the process and method in which students learn knowledge is shown in Fig. 1. During the class, teachers impart new knowledge to students through knowledge lecture and in other forms. After class, students can review and consolidate knowledge by finishing assignments, so as to sublime the internalization of knowledge they have learned in the class and truly digest the them in the classrooms.

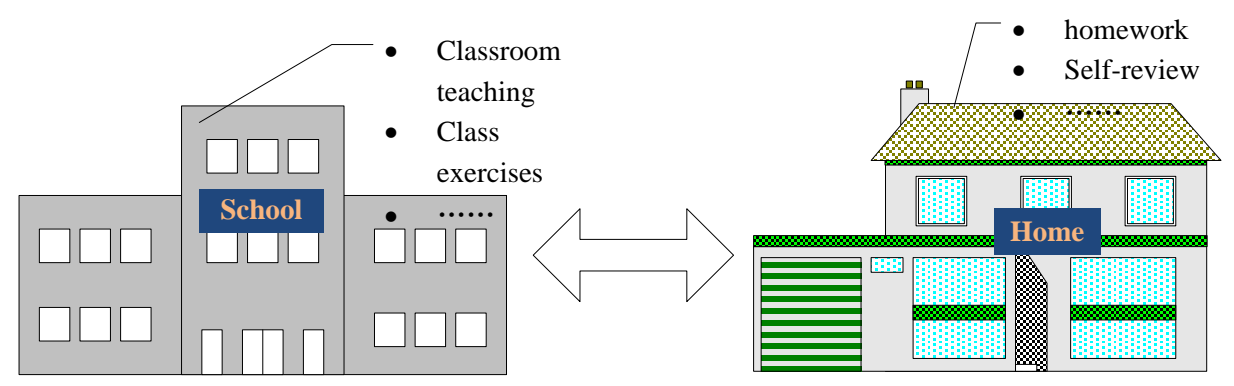

Figure 1. Traditional learning mode.

While for the FC instruction model (Figure 2), after the class, students can learn new knowledge before class at their own paces by virtue of the scaffolds provided by teachers such as learning resources and tasks (evaluation exercises). Then the teacher helps students analyze real learning difficulties encountered by them by checking the completion of their learning tasks. In the class, teachers organize guided activities in allusion to these difficulties to further consolidate the new knowledge students have learned before class so as to achieve the purpose of students' knowledge internalization. 


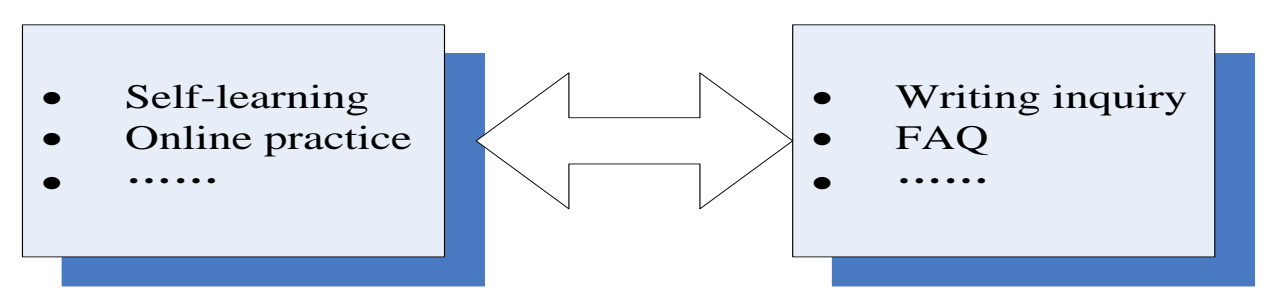

Figure 2. Flip classroom learning process.

\section{Flip classroom teaching system design}

As above, the author believes that the FC must include three phases: delivery, diagnosis, and internalization. After integrating architectures of the above three activities in the FC model, the author proposes the "transmission-diagnosis-internalization" FC architecture, and builds the MCOV-based FC model, as shown in Fig. 3, based on Professor Robert Talbert's “pre-class - in-class” FC model (Fig. 3).

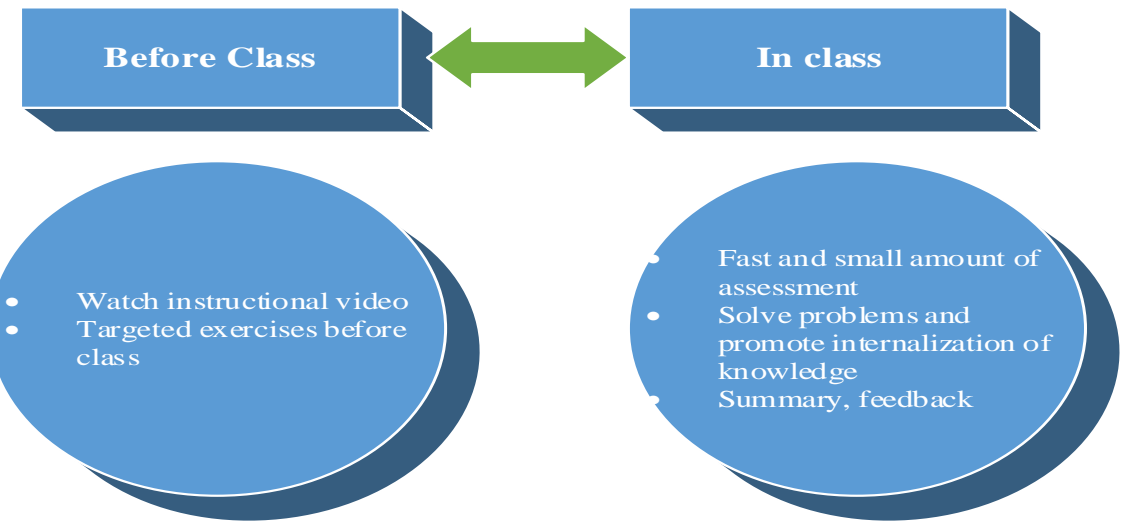

Figure 3. "Pre-classroom" flip classroom teaching model.

In the "delivery" phase, the model mainly uses micro-curriculum videos to complete the transference of new knowledge. The micro-curriculum videos can be sourced in two ways: the first is to select excellent open education resources on the Internet, such as Khan Academy, Micro-curriculum networks, and other excellent micro-learning video websites. Although this greatly reduces the workload of teachers, the micro-curriculum resources from the networks may not well fit the bill for actual teaching objectives. Therefore, this model is more restrictive. Second, the teachers make micro-course at the sole discretion, so that the video content can be more fit in with the actual teaching objectives. Micro-course video needs to be as concise as possible. It is suggested that only audio and writing books be recorded so that students can focus on their attention when watching them. In addition, each video is suitable for explaining 1-2 knowledge points, and controlled within 10 minutes. 


\section{In School}

Outside school

\section{Transfer \\ Pass new \\ knowledge}

\section{Diagnosis}

Prepositional

exercises to

diagnose

difficult

learning
Internalization

Guided

classroom

activities

internalize

knowledge

Figure 4. Android-based flip classroom teaching mode.

The MCOV-based O-AB-AB teaching model is an integration of OI and AB. As shown in Fig. 5, the model has undergone three "flips", but every time, the micro-curriculum is presented at different chances and roles played, and they are mutually connected and supplement each other.

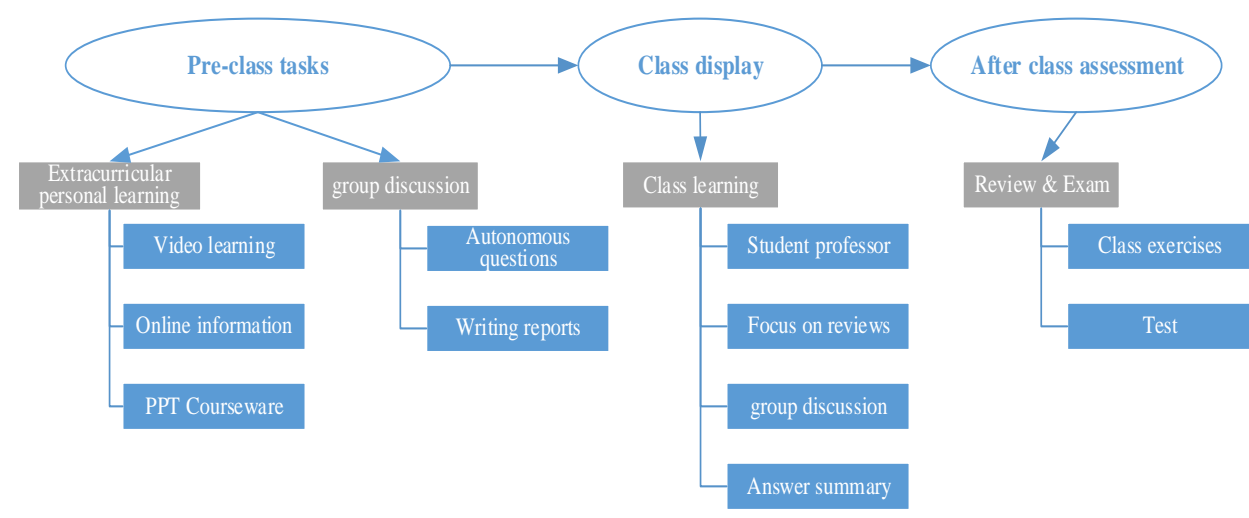

Figure 5. Android-based pathology flip classroom design.

This model mainly achieves three times of flip classroom instruction based on micro-curriculum. The first flip is done for in-class and out-of-class. Similar to the OI model, the "delivery" and "diagnosis" phases run after class where new knowledge will be learned with micro-curriculum videos; "Internalization" is arranged in class; the second flip is the first half of classroom teaching. Firstly, students can consolidate knowledge with the help of micro-curriculum videos. Later, stratified teaching help students with learning difficulties and top learners to construct their own new knowledge. The third flip is in the second half of the classroom. Like the above two, micro-curriculum helps expand knowledge. In the end, students internalize the knowledge they have learned through activities such as Q\&A and summary and feedback. 


\section{Students' evaluation of the effect of flipping classroom teaching}

Table 1

\begin{tabular}{lcc} 
Student's Flipped Classroom Teaching Participation [n $(\%)]$ & YES & NO \\
\hline Content & $118(81.6)$ & $10(8.4)$ \\
\hline Students listen carefully when they lecture & $88(83.4)$ & $31(17.6)$ \\
Participate in PPT courseware production & $113(84.1)$ & $7(5.8)$ \\
Can answer questions from the teacher & $105(88.3)$ & $14(11.8)$ \\
Reasonable time for the teacher to arrange flipping classes & $117(88.3)$ & $3(1.7)$ \\
You think teacher-guided student discussion is useful & $110(83.4)$ & $8(7.6)$ \\
Student feedback is useful & $118(99.2)$ & $1(0.8)$ \\
The teacher's summary is useful &
\end{tabular}

Table 2

Student Evaluation of Flipping Classroom Teaching [n (\%)]

\begin{tabular}{lccc}
\hline Item & Agree & Very agree & Not agree \\
\hline Promote knowledge understanding, and application & $73(60.5)$ & $45(37.8)$ & $3(1.7)$ \\
Stimulate interest in learning & $68(58.0)$ & $47(38.5)$ & $3(3.5)$ \\
Promote the ability to actively observe and identify problems & $78(66.4)$ & $33(37.7)$ & $7(5.8)$ \\
Improve self-critical thinking skills & $64(53.8)$ & $53(43.7)$ & $3(3.5)$ \\
Continue to apply the teaching mode later & $61(51.3)$ & $51(43.8)$ & $7(5.8)$ \\
Promoting exploration and questioning spirit cultivation & $70(58.8)$ & $46(38.7)$ & $3(3.5)$ \\
Helps foster collaboration & $84(78.0)$ & $33(18.5)$ & $3(3.5)$ \\
Help yourself build self-confidence & $68(58.0)$ & $40(33.6)$ & $10(8.4)$ \\
Helps improve problem solving skills & $85(71.4)$ & $30(35.3)$ & $4(3.4)$ \\
Promote effective communication with teachers and peers & $100(84.0)$ & $18(16.0)$ & $0(0.0)$ \\
Helps to improve self-reflection & $73(61.3)$ & $41(34.5)$ & $5(4.3)$ \\
Help improve self-learning ability & $73(60.5)$ & $45(37.8)$ & $3(1.7)$ \\
\hline
\end{tabular}

Among the 119 students who have participated in FC learning, 60.5\% believe that the model can promote knowledge comprehension, memory and application, and 58.0\% think that the model could trigger their interests in learning. There are $5.9 \%$ students who disagree to continue applying the model in the future. Additionally, the students who agree that "this model is conducive to cultivating collaboration skills, improving their competences to solve problems and learn actively, and intensifying effective communication between teachers and peers" account for over 70\%. It is suggested that this model is helpful for the overall development of students since students are very satisfied with it, and it also contributes to communication between teachers and students, students and students (see Table 1).

\section{Conclusion}

This paper systematically describes the concept of MCOV and FC, MCOV's classification, and analyzed the applicability of different types of micro-curriculum FC models in the searching five knowledge domains from the perspective of Gagnes theory of instruction. The author also combs the basic FC instruction models with reference to pertinent literature, and further proposes three types of FC instruction models based on MCOV, i.e. O-I, A-B and O-AB-AB, as a theoretical support for carrying out FC teaching based on microcurriculum. In the end, the author wraps up the teaching process of FCs based on micro-curriculum and designs a teaching schedule in this mode, which further improves the operability of the three types of teaching models. 


\section{References}

Allen-Ramdial, S. A. A., \& Campbell, A. G. (2014). Reimagining the pipeline: Advancing STEM diversity, persistence, and success. BioScience, 64(7), 612-618.https://dx.doi.org/ 10.1093/biosci/biu076

Gouia, R., \& Gunn, C. (2016). Making mathematics meaningful for freshmen students: investigating students' preferences of pre-class videos. Research \& Practice in Technology Enhanced Learning, 11(1), 2. https://dx.doi.org/10.1186/s41039-015-0026-9

Hwang, G. J., Lai, C. L., \& Wang, S. Y. (2015). Seamless flipped learning: a mobile technology-enhanced flipped classroom with effective learning strategies. Journal of Computers in Education, 2(4), 449-473. https://dx.doi.org/10.1007/s40692-015-0043-0

Liou, W. K., Bhagat, K. K., \& Chang, C. Y. (2016). Beyond the flipped classroom: A highly interactive cloudclassroom (HIC) embedded into basic materials science courses. Journal of Science Education and Technology, 25(3), 460-473. https://dx.doi.org/10.1007/s10956-016-9606-8

Muir, T., \& Geiger, V. (2016). The affordances of using a flipped classroom approach in the teaching of mathematics: A case study of a grade 10 mathematics class. Mathematics Education Research Journal,28(1), 1-23. https://dx.doi.org/10.1007/s13394-015-0165-8

Mustapha, S. M., Rahman, N. S. N. A., \& Yunus, M. M. (2010). Factors influencing classroom participation: A case study of Malaysian undergraduate students. Procedia - Social and Behavioral Sciences, 9(9), 10791084. https://dx.doi.org/10.1016/j.sbspro.2010.12.289

Subramaniam, M. M., Ahn, J., Fleischmann, K. R., \& Druin, A. (2012). Reimagining the role of school libraries in STEM education: Creating hybrid spaces for exploration. The Library Quarterly, 82(2), 161-182. https://dx.doi.org/ 10.1086/664578

Yang, C. C. R. (2017). An investigation of the use of the "Flipped Classroom" pedagogy in secondary English language classrooms. Journal of Information Technology Education Innovations in Practice, 16(1), 1-20. https://dx.doi.org/10.28945/3635

Zainuddin, Z., \& Attaran, M. (2015). Malaysian students' perceptions of flipped classroom: A case study. Innovations in Education \& Teaching International, 53, 660-670. https://dx.doi.org/ 10.1080/14703297.2015.1102079

Zengin, Y. (2017). Investigating the use of the Khan Academy and mathematics software with a flipped classroom approach in mathematics teaching. Journal of Educational Technology \& Society, 20(2), 89-100. 